International Journal of Biology, Pharmacy and Allied Seiences (IJBPAS)

'A Bridge Betuen Caboratory and Q Qnder'

WwW.ijbpas,com

\title{
CONVERGENCE OF PICARD-S HYBRID ITERATION PROCESS FOR STRONGLY ACCRETIVE OPERATOR
}

\author{
IMAN A. HUSSAIN \\ Department Mathematics and Computer Applications Al-Nahrain University -College Science, \\ Baghdad, Iraq \\ E Mail: iah@sc.nahrainuniv.edu \\ Received $3^{\text {rd }}$ Jan. 2018; Revised $7^{\text {th }}$ Feb. 2018; Accepted $19^{\text {th }}$ March 2018; Available online $1^{\text {st }}$ May 2018 \\ DOI: https://doi.org/10.31032/IJBPAS/2018/7.5.4437
}

\begin{abstract}
Study deals with the convergence of the fixed point of the pseudo-contractive mapping by using Picard-S Hybrid iteration method in the uniformly smooth Banach. This research is a generalization of many of the sources referred to here.
\end{abstract}

\section{INTRODUCTION}

In computational mathematics, an iterative method is a mathematical procedure that generates a sequence of improving approximate solutions for a class of problems. One of this class is to finding the fixed point of operator. There are many theorems talked about finding fixed point for different type of operators by using another iterative, the common theorem in fixed point called Banach fixed point which use Picard iterative. The Banach fixed point theorem have been studied extensively by various authors for approximating fixed points of nonlinear operators in Banach space. C. E. Chidume [3], [5], [7], [8], [11], [13] and [16] are introduced and studied Mann and Ishikawa iteration process to approximate fixed points. Recently, in 1998 Chidume [4],
Liue [15], Osilike [21] and $\mathrm{Xu}$ [25] introduced the concepts of Ishikawa and Mann iterative process with errors for nonlinear strongly accretive operators in uniformly smooth Banach spaces. Gloswinski and Le Tallec [9] used threestep iterative schemes to find the approximate solutions of the elastoviscoplasticity problems, liquid crystal theory, and eigen-value problem. It has been shown in [9] that the three-step iterative scheme gives better numerical results than the two-step and one-step. In 2002, Noor, Rassias and Huang [19] had suggested the three-step iteration process for solving the nonlinear strongly accretive operator equations in real uniformly smooth Banach spaces. Plubteing and Wangkeeree [22] introduced and studied a 
multi-step scheme with errors to approximate fixed points of asymptotically nonexpansive operator in a Banach space. In our research we proved the theory of convergence of the fixed point of pseudocontractive mapping, where the search [10] proved a Picard-S Hybrid is faster iteration among the other as Mann, Ishikawa, Noor, CR iterations and others. As well research [10] used contraction mapping while in our research we used the generalized mapping.

Algorithm 1.1: Let $C$ be a nonempty convex subset of a uniformly smooth Banach space $X$ and let $T: C \rightarrow C$ be operator. For any given $x \in C$, and a fixed positive integer $N$, the sequence $\left\{x_{n}\right\}$ defined by

$$
\begin{gathered}
x_{0} \in C \\
x_{n+1}=T y_{n} \\
y_{n}=\left(1-\alpha_{n}\right) T x_{n}+\alpha_{n} T z_{n}(1.1) \\
z_{n}=\left(1-\beta_{n}\right) x_{n}+\beta_{n} T x_{n}, n \quad \in \mathbb{N}
\end{gathered}
$$

where $\left\{\alpha_{n}\right\}_{n=0}^{\infty}$ and $\left\{\beta_{n}\right\}_{n=0}^{\infty}$ are sequences in $[0,1] \quad \alpha_{n}+\beta_{n}=1$. The above algorithm are called a Picard-S Hybrid iteration.

Our paper is organized as follows. In section two we give two preliminary lemmas and some definitions. In section three we obtain the strong convergence theorems of Picard- S Hybrid iterative scheme for approximating fixed point of nonlinear strongly pseudo-contractive operator or solutions of nonlinear strongly accretive operator.

\section{2- Preliminaries}

Now, we recall the well-known concepts and results. Throughout we assume that $X$ is a real Banach space and $X^{*}$ is the dual space of $\mathrm{X}$. Let $\mathrm{J}$ denoted the normalized duality from $\mathrm{X}$ to $2^{X^{*}}$ defined by

$J(x)=\left\{j \in X^{*}:\langle x, j\rangle=\|x\|\|j\|=\|x\|^{2}\right\} \ldots$

Where $\langle.,$.$\rangle denote the generalized duality$ pairing.

Definition 2.1 [23]: A mapping $T: X \rightarrow X$ is called strongly accretive if there exists a constant $0<k<1$ such that for each $x, y \in X$ there is a $j(x-y) \in J(x-y)$ satisfying,

$\langle T x-T y, j(x-y)\rangle \geq k\|x-y\|^{2} \ldots$

Definition 2.2 [12]: An operator $T$ with domain $D(T)$ and range $R(T)$ in $X$ is called strongly pseudo-contractive if for all $x, y \in D(T)$, there exists $j(x-y) \in J(x-$ $y$ ) and constant $0<k<1$ such that

$\langle T x-T y, j(x-y)\rangle \leq(1-k)\|x-y\|^{2}$.

In [6], can show for any given $f \in X$ the equation $T x=f$ has a unique solution if $T: X \rightarrow X$ is strongly accretive and continuous, on $X$ is uniformly smooth and $T: X \rightarrow X$ is strongly accretive and demicontinuous (i.e, $\quad x_{n} \rightarrow x \Rightarrow T x_{n}-$ $T X)$. Martin [17] has also proved that if $T: X \rightarrow X$ is continuous and accretive then for any given $f \in X$ the equation $x+$ $T x=f$ has a unique solutions. In the following, we shall give the two lemmas needed in the main results.

Lemma2.3 [25]: Let $X$ be a real uniformly smooth Banach space and let $J: X \rightarrow 2^{X^{*}}$ be the normalized duality mapping. Then for any $x, y \in X$ we have

$$
\begin{aligned}
& \|x+y\|^{2} \leq\|x\|^{2}+2\langle y, j\rangle, \\
& \forall j(x+y) \in J(x+y) .
\end{aligned}
$$


Lemma 2.4 [15]: Let $\left\{a_{n}\right\}_{\boldsymbol{n}=\mathbf{0}}^{\infty},\left\{b_{n}\right\}_{\boldsymbol{n}=\mathbf{0}}^{\infty}$ and $\left\{c_{n}\right\}_{\boldsymbol{n}=\mathbf{0}}^{\infty}$ three nonnegative real sequences satisfying

$a_{n+1} \leq\left(1-t_{n}\right) a_{n}+b_{n}+c_{n}, \quad n \geq 0$ with $t_{n} \in[0,1)$,

$\sum t_{n}=+\infty, b_{n}=o\left(t_{n}\right)$ and

$\sum c_{n}<+\infty$. Then $\lim _{n \rightarrow \infty} a_{n}=0$.

\section{RESULTS}

In section three, we give prove of the strong convergence of Picard-S Hybrid iterative process defined by (1.1) for the strongly pseudo-contractive operators.

Theorem 3.1: Let $X$ be a real uniformly smooth Banach space and let $\mathrm{C}$ be a nonempty bounded closed convex subset of $\mathrm{X}$, and let T: $\mathrm{C} \rightarrow C$ be strongly pseudocontractive mapping with bounded range. Suppose the sequence $\left\{x_{n}\right\}$ be defined by (1.1), where $\left\{\alpha_{n}\right\}$ and $\left\{\beta_{n}\right\}$ are sequence in $[0,1]$ with $\propto_{n}+\beta_{n}=1$ and satisfying the conditions:

(i) $\quad \lim _{\mathrm{n} \rightarrow \infty} \beta_{n}=0$, $\sum_{n=0}^{\infty} \beta_{n}=+\infty$;

(ii) $\lim _{n \rightarrow \infty} \propto_{n}=0$

$$
\sum_{n=0}^{\infty} \propto_{n}<+\infty \text {. }
$$

Then $\left\{x_{n}\right\}$ convergences strongly to the unique common fixed point of $\mathrm{T}$.

Proof: In [12] guarantees the map satisfying condition (2.3) has unique fixed point of q. Since $C$ is bounded and $T$ is bounded rang then T(TX) is bounded, this yields,$\exists \mathrm{M}<\infty$ such that

$\left\|x_{n+1}-\mathrm{q}\right\|<M, \quad \forall n \in N$.

$$
\begin{aligned}
& \left\|z_{n}-q\right\|^{2}=\left\|\left(1-\beta_{n}\right) x_{n}+\beta_{n} T x_{n}-q\right\|^{2} \\
= & \left\|\left(1-\beta_{n}\right)\left(x_{n}-q\right)+\beta\left({ }_{n} T x_{n}-q\right)\right\|^{2} \\
\leq & \left(1-\beta_{n}\right)^{2}\left\|x_{n}-q\right\|^{2}+2 \beta_{n}\left\langle T x_{n}-q, j\left(z_{n}-q\right)\right\rangle
\end{aligned}
$$

$\leq\left(1-\beta_{n}\right)^{2}\left\|x_{n}-q\right\|^{2}+2 \beta_{n}\left\langle\mathrm{~T} x_{n}-\mathrm{q}, \mathrm{j}\left(x_{n}-\right.\right.$

q)

$$
\begin{aligned}
+ & 2 \beta_{n}\left\langle\mathrm{~T} x_{n}-\mathrm{q}, \mathrm{j}\left(z_{n}-\mathrm{q}\right)-\mathrm{j}\left(x_{n}-\mathrm{q}\right)\right\rangle \\
\leq & \left(1-\beta_{n}\right)^{2}\left\|x_{n}-q\right\|^{2}+2 \beta_{n}(1-\mathrm{k}) \| x_{n}- \\
& q 2+2 \beta n v n 1
\end{aligned}
$$

Where $\quad v_{n}^{1}=\left\langle\mathrm{T} x_{n}-\mathrm{q}, \mathrm{j}\left(z_{n}-\mathrm{q}\right)-\mathrm{j}\left(x_{n}-\mathrm{q}\right)\right\rangle$. Let $b_{n}=2 \beta_{n} v_{n}^{1}$, since $\beta_{n} \rightarrow 0$ as $n \rightarrow \infty$ there exists $m_{1} \in N$ such that $\beta_{n}-\mathrm{k} \leq 0$ for all $n \geq m_{1}$.

Hence

$\left\|z_{n}-q\right\|^{2} \leq\left(1-k \beta_{n}\right)\left\|x_{n}-q\right\|^{2}+\quad+2 \beta_{n} v_{n}^{1}$ $n \geq m_{1}$.

Now,

$$
\begin{gathered}
\left\|y_{n}-q\right\|^{2}=\left\|\left(1-\propto_{n}\right) T x_{n}+\propto_{n} T z_{n}-q\right\|^{2} \\
=\|\left(1-\propto_{n}\right)\left(T x_{n}-q\right)+ \\
\quad+\propto n(T z n-q) 2 \\
\leq\left(1-\propto_{n}\right)^{2}\left\|T x_{n}-q\right\|^{2}++2 \propto_{n}\left\langle\mathrm{~T} z_{n}-\right. \\
\quad \mathrm{q}, \mathrm{j}(y n-\mathrm{q}) \\
\leq\left(1-\propto_{n}\right)^{2}(1-\mathrm{k})\left\|x_{n}-q\right\|^{2}+ \\
2 \propto_{n}(1-\mathrm{k})\left\|z_{n}-q\right\|^{2} \\
+2 \propto_{n}\left\langle\mathrm{~T} z_{n}-\mathrm{q},\left(y_{n}-\mathrm{q}\right)-\mathrm{j}\left(z_{n}-\mathrm{q}\right)\right\rangle \\
=\left(1-\propto_{n}\right)^{2}(1-\mathrm{k})\left\|x_{n}-q\right\|^{2}+ \\
2 \propto_{n}(1-\mathrm{k})\left\|z_{n}-q\right\|^{2} \\
+2 \propto_{n} v_{n}^{2}
\end{gathered}
$$

Where

$v_{n}^{2}=$

$\left\langle\mathrm{T} z_{n}-\mathrm{q}, \mathrm{j}\left(y_{n}-\mathrm{q}\right)-\quad \mathrm{j}\left(z_{n}-\right.\right.$ q.

This implies that

$$
\begin{gathered}
\left\|y_{n}-q\right\|^{2} \leq 2(1-k)\left\|x_{n}-q\right\|^{2}+ \\
4(1-k) \propto_{n} \beta_{n} v_{n}^{1}+2 \propto_{n} v_{n}^{2} \\
\leq\left(1-k \propto_{n} \beta_{n}\right)\left\|x_{n}-q\right\|^{2}+ \\
4(1-k) \propto_{n} \beta_{n} v_{n}^{1}+2 \propto_{n} v_{n}^{2}
\end{gathered}
$$

Next, we explain 


$$
\begin{gathered}
\begin{array}{c}
\left\|x_{n+1}-q\right\|^{2}=\left\|T y_{n}-q\right\|^{2} \\
=\left\langle T y_{n}-q, \mathrm{j}\left(y_{n}-\mathrm{q}\right)\right\rangle
\end{array} \\
\leq(1-k)\left\|y_{n}-q\right\|^{2} \\
\leq 2(1-k)^{2}\left(1-k \propto_{n} \beta_{n}\right)\left\|x_{n}-q\right\|^{2}+ \\
\quad b_{n}+c_{n} \\
\leq\left(1-k \propto_{n} \beta_{n}\right)\left\|x_{n}-q\right\|^{2}+b_{n}+c_{n}
\end{gathered}
$$

Where $b_{n}=4(1-\mathrm{k})^{2} \propto_{n} \beta_{n} v_{n}^{1}, \quad c_{n}=2(1-$ k) $\propto_{n} v_{n}^{2}$.

This implies that

$\left\|x_{n+1}-q\right\|^{2} \leq a_{n}\left\|x_{n}-q\right\|^{2}+b_{n}+c_{n}$

where $a_{n}=\left(1-\mathrm{k} \beta_{n}\right)$

Then (3.4) reduces to

$a_{n+1} \leq\left(1-t_{n}\right) a_{n}+b_{n}+c_{n}, n \geq m_{1}$

Where $\left\|x_{n}-q\right\|^{2}=a_{n}$ and $\mathrm{k} \beta_{n}=t_{n}$.

Now, we show that

$\left\langle\mathrm{T} x_{n}-\mathrm{q}, \mathrm{j}\left(z_{n}-\mathrm{q}\right)-\mathrm{j}\left(x_{n}-\mathrm{q}\right)\right\rangle \rightarrow 0$ as $n \rightarrow \infty$, and $\left\langle\mathrm{T} z_{n}-\mathrm{q}, \mathrm{j}\left(z_{n}-\mathrm{q}\right)-\mathrm{j}\left(y_{n}-\mathrm{q}\right)\right\rangle \rightarrow 0 \quad$ as $n \rightarrow \infty$. Since $\lim _{n \rightarrow \infty} \beta_{n}=0$,

$$
\begin{aligned}
& \left\|\left(z_{n}-q\right)-\left(x_{n}-q\right)\right\|=\left\|\left(1-\beta_{n}\right) x_{n}+\beta_{n} T x_{n}-x_{n}\right\| \\
& \quad=\left\|x_{n}-\beta_{n} T x_{n}+\beta_{n} T x_{n}-x_{n}\right\| \\
& =\beta_{n}\left\|x_{n}-T x_{n}\right\| \rightarrow 0 \\
& \quad \text { as } n \rightarrow \infty .
\end{aligned}
$$$$
\left\|\left(z_{n}-q\right)-\left(y_{n}-q\right)\right\|
$$$$
=\|\left(1-\beta_{n}\right) x_{n}+\beta_{n} T x_{n}
$$$$
-\beta_{n} T x_{n}-\left(1-\beta_{n}\right) T z_{n} \|
$$

$=\|\left(1-\beta_{n}\right)\left(x_{n}-T z_{n} \|\right.$

$=\left(1-\beta_{n}\right)\left\|x_{n}-T z_{n}\right\| \rightarrow 0$ as $n \rightarrow \infty$.

This, we give $\left\{x_{n}-\mathrm{q}\right\}_{\boldsymbol{n}=\mathbf{1}}^{\infty},\left\{z_{n}-\mathrm{q}\right\}_{\boldsymbol{n}=\mathbf{1}}^{\infty}$ and $\left\{y_{n}-\mathrm{q}\right\}_{n=1}^{\infty}$ are bounded sets, from Lemma 2.2, since $\mathrm{X}$ is uniformly smooth Banach space, $j$ is single valued and uniformly continuous on any bonded subsets of $X$ this implies that

$\left\langle\mathrm{T} x_{n}-\mathrm{q}, \mathrm{j}\left(z_{n}-\mathrm{q}\right)-\mathrm{j}\left(x_{n}-\mathrm{q}\right)\right\rangle \rightarrow 0$ as $n \rightarrow \infty$,

and

$\left\langle T z_{n}-\mathrm{q}, \mathrm{j}\left(z_{n}-\mathrm{q}\right)-\mathrm{j}\left(y_{n}-\mathrm{q}\right)\right\rangle \rightarrow 0$ as $n \rightarrow \infty$

This implies that

$\lim _{n \rightarrow \infty}\left(\frac{b_{n}}{k \beta_{n}}\right)=0$. Therefore $b_{n}=o\left(k \beta_{n}\right)$.

We note that $\sum_{n=1}^{\infty} c_{n}<\infty$. Then, by lemma 2.3, $\quad \lim _{n \rightarrow \infty}\left\|x_{n}-q\right\|=0$ and therefore $\quad x_{n} \rightarrow q \in X \quad$ as $\quad n \rightarrow \infty$. Recently, we will show that $q$ is a unique common fixed point of $T$. Let $q^{*} \in F$ is a set of fixed point of $T$, we can show

$$
\begin{aligned}
\left\|q-q^{*}\right\|=\left\langle\mathrm{Tq}-\mathrm{T} q^{*}, \mathrm{j}\left(\mathrm{q}-q^{*}\right)\right\rangle \\
\leq(1-\mathrm{k})\left\|q-q^{*}\right\|,
\end{aligned}
$$

since $k \in(0,1)$, we have the equality that $q=q^{*}$.

Corollary 3.2: Let $T$ be maps from a real uniformly smooth Banach space $X$ to itself. Define $\mathrm{S}: \mathrm{X} \rightarrow X$ by $\mathrm{Sx}=\mathrm{x}-\mathrm{Tx}+$ $\mathrm{f}$, where $\mathrm{f} \in \mathrm{X}$ is fixed and suppose that the range of $S$ is bounded. Then the sequence $\left\{x_{n}\right\}$ generated by Picard-S Hybrid iteration is defined by

$$
\begin{gathered}
x_{0} \in X \\
x_{n+1}=S y_{n} \\
y_{n}=\left(1-\alpha_{n}\right) S x_{n}+\alpha_{n} S z_{n} \\
z_{n}=\left(1-\beta_{n}\right) x_{n}+\beta_{n} S x_{n}, n \in \mathbb{N}
\end{gathered}
$$

Satisfy the following property:

(i) $\quad \lim _{\mathrm{n} \rightarrow \infty} \beta_{n}=0$,

(ii) $\quad \sum_{n=0}^{\infty} \beta_{n}=+\infty$;

(iii) $\lim _{n \rightarrow \infty} \propto_{n}=0$

(iv) $\quad \sum_{n=0}^{\infty} \propto_{n}<+\infty$. 
And $\alpha_{n}+\beta_{n}=1$ for all $n \in \mathbb{N}$. Then the sequence $\left\{x_{n}\right\}$ convergence strongly to the unique solution of the equation $\mathrm{Tx}=\mathrm{f}$.

Proof: Let T satisfy the condition (2.2),

Then

$\langle T x-T y, j(x-y)\rangle \geq k\|x-y\|^{2} \quad$ for all $x, y \in X$

Now, we show that

$$
\begin{aligned}
& \langle S x-S y, j(x-y)\rangle=\langle(x-T x+f)- \\
& y-T y+f, j x-y . \\
& \quad=\langle x-y, j(x-y)\rangle-\langle T x-T y, j(x-y)\rangle \\
& \quad \leq\|\mathrm{x}-q\|^{2}-k\|\mathrm{x}-q\|^{2}=(1-k)\|\mathrm{x}-q\|^{2}
\end{aligned}
$$

So, $\mathrm{S}$ is strongly pseudo-contractive mapping. Since the range of $S$ is bounded.

The application of the same as the previous steps in theory (3.1) we note that the sequence $\left\{x_{n}\right\}$ convergence strongly to the solution of the equation $\mathrm{Tx}=\mathrm{f}$.

Corollary 3.3:([19)] Let $X$ be a real uniformly smooth Banach space and let $C$ be a nonempty bounded closed convex subset of $X$, and let T: $\mathrm{C} \rightarrow C$ be a strongly pseudo-contractive mapping. Let $\mathrm{q}$ be a fixed point of $\mathrm{T}$ and let the Ishikawa iteration sequence $\left\{x_{n}\right\}$ be defined by (1.2): satisfying:

$\lim _{\mathrm{n} \rightarrow \infty} \propto_{n}=0, \quad \quad \lim _{\mathrm{n} \rightarrow \infty} \beta_{n}=0$, $\lim _{n \rightarrow \infty} \gamma_{n}=0 \sum_{n=0}^{\infty} \propto_{n}=+\infty$.

Then $\left\{x_{n}\right\}$ converges strongly to the unique fixed point of $\mathrm{T}$.

$$
\text { ForN }=2, \quad T_{1}=T_{2}, \propto_{n}=\propto_{n}^{1},
$$

$\dot{\beta}_{n}=\beta_{n}^{1}, \quad \dot{\gamma}_{n}=\gamma_{n}^{1}, \quad \propto_{n}=\propto_{n}^{1}, \beta_{n}=$ $\beta_{n}^{1}, \gamma_{n}=\gamma_{n}^{1}$, in theorem 3.1, we can obtain Ishikawa-type Convergence result for two mappings.

Corollary 3.4:([25)] Let $X$ be a real uniformly smooth Banach space and let $C$ be a nonempty bounded closed convex subset of $X$, and let T: $\mathrm{C} \rightarrow C$ be a strongly pseudo-contractive mapping. Let $\mathrm{q}$ be a fixed point of $\mathrm{T}$ and let the Ishikawa iteration sequence $\left\{x_{n}\right\}$ be defined by (1.3): satisfying the following conditions:

$$
\begin{aligned}
& \lim _{\mathrm{n} \rightarrow \infty} \beta_{n}=0 \\
& \sum_{n=0}^{\infty} \beta_{n}=+\infty ; \\
& \lim _{\mathrm{n} \rightarrow \infty} \hat{\beta}_{n}=0 ; \\
& \lim _{\mathrm{n} \rightarrow \infty} \hat{\gamma}_{n}=0, \quad \text { and } \\
& \lim _{\mathrm{n} \rightarrow \infty} \gamma_{n}=0, \quad \text { and } \\
& \sum_{n=0}^{\infty} \gamma_{n}<+\infty .
\end{aligned}
$$

Then $\left\{x_{n}\right\}$ converges strongly to the unique fixed point of $\mathrm{T}$.

Now, we give the multi-step iterative process with errors for solving nonlinear strongly accretive operators $T_{i}=\mathrm{f}$ for $\mathrm{i}=1, \ldots, \mathrm{N}$. Where it was based on theory 3.2 and theory 3.3 in the proof of the following theory.

Theorem 3.5:([12]) Let $X$ be a real uniformly smooth Banach space and let $T_{1}, \ldots, T_{N}: \mathrm{X} \rightarrow X$ be a strongly accretive mappings. For a fixed $f \in X$, define $S_{1}, \ldots, S_{N}: \mathrm{X} \rightarrow X$ by $S_{i} \mathrm{x}=\mathrm{x}-T_{i} \mathrm{x}+\mathrm{f}$ for all $\mathrm{i}=1, \ldots, \mathrm{N}$ and suppose that each range of $S_{i}$ are bounded. For arbitrary $x_{1} \in X$ the sequence $\left\{x_{n}\right\}$ with errors is defined by

$$
\left\{\begin{array}{c}
x_{1} \in X, \\
x_{n}^{1}=\propto_{n}^{1} x_{n}+\beta_{n}^{1} S_{1} x_{n}+\gamma_{n}^{1} u_{n}^{1}, \\
x_{n}^{2}=\propto_{n}^{2} x_{n}+\beta_{n}^{2} S_{2} x_{n}^{1}+\gamma_{n}^{2} u_{n}^{2}, \\
\vdots \\
x_{n+1}=x_{n}^{N}=\propto_{n}^{N} x_{n}+\beta_{n}^{N} S_{N} x_{n}^{N-1}+\gamma_{n}^{N} u_{n}^{N}
\end{array}\right.
$$$$
, n \geq 1
$$ 
where $\left\{u_{n}^{1}\right\},\left\{u_{n}^{2}\right\}, \ldots,\left\{u_{n}^{N}\right\}, \quad$ are bounded sequences in $X$ and $\left\{\propto_{n}^{1}\right\},\left\{\propto_{n}^{2}\right\}, \ldots,\left\{\propto_{n}^{N}\right\}$, $\left\{\beta_{n}^{1}\right\},\left\{\beta_{n}^{2}\right\}, \ldots,\left\{\beta_{n}^{N}\right\},\left\{\gamma_{n}^{1}\right\},\left\{\gamma_{n}^{2}\right\}, \ldots,\left\{\gamma_{n}^{N}\right\}$ are sequences in $[0,1]$ with $\propto_{n}^{i}+\beta_{n}^{i}+$ $\gamma_{n}^{i}=1$ for $\mathrm{i}=1, \ldots, \mathrm{N}$ and satisfying the following conditions:

$$
\begin{aligned}
& \lim _{\mathrm{n} \rightarrow \infty} \beta_{n}^{N}=0 \text { for all } \\
& \mathrm{i}=1,2, \ldots, \mathrm{N} \text { and } \sum_{n=0}^{\infty} \beta_{n}^{N}= \\
& +\infty ; \\
& \lim _{\mathrm{n} \rightarrow \infty} \gamma_{n}^{i}=0, \quad \text { for all } \\
& \mathrm{i}=1,2, \ldots, \mathrm{N} \text { and } \sum_{n=0}^{\infty} \gamma_{n}^{N}< \\
& +\infty .
\end{aligned}
$$

If the systems of operator $T_{1} \mathrm{x}=\mathrm{f}, \ldots$, $T_{N} \mathrm{x}=\mathrm{f}$ has solution in $\mathrm{X}$, then the sequence $\left\{x_{n}\right\}$ converges strongly to the unique solution of operator equations $T_{1} \mathrm{x}=\mathrm{f}, \ldots, T_{N} \mathrm{x}=\mathrm{f}$.

\section{References:}

[1] F. E. Browder, Nonlinear of nonexpansive and accretive type in Banach spaces, Bull. Amer. Math. Soc. 73 (1967) 875-882.

[2] F. E. Browder, Nonlinear operations and nonlinear equations of evolution in Banach spaces, Proc. Sympos. Pure Math. 18 (2) (1976).

[3] C. E. Chidume, Approximation of fixed point of strongly pseudocontractive mappings, Proc Amer. Math Soc. 120 (1994) 545-551.

[4] C. E. Chidume, Convergence theorems for strongly pseudocontractive and strongly accretive maps, J. Math. Anal. Appl. 228 (1998 254-264).

[5] C. E. Chidume, M. O. Osilike, Ishikawa iteration process for Lipschitz strongly accretive mappings, J. Math. Anal. Appl. 192 (1995) 727-741.
[6] K. Deimling, Nonlinear Functional Analysis Springer-Verlag, Berlin, 1985.

[7] L. Deng, An Iterative process for nonlinear Lipschizian and strongly accretive mappings in uniformly convex and uniformly smooth Banach spaces, Acta Appl. Math. 32 (1993) 183-196.

[8] L. Deng, X.P. Ding, Iterative approximation of Lipschiz strictly pseudo-contractive mappings in uniformly smooth Banach spaces, Nonlinear Anal. 24 (1995) 981-987.

[9] R. Glowinski, P.Le. Tallec, Augmented Lagrangian and Operator-Spliting Methods in Nonlinear Mechanics, SIAM, Philadelhia, 1989.

[10] F. Gursoy and V. Karakaya, A Picard-S Hybrid type iterative method for solving differential equation with retarded Argument (2014), arXiv: 1403.2546.

[11] Z. Haiyun, J. Yunting, Approximation of fixed points of strongly pseudocontractive maps without Lipschitz assumption, Proc. Amer. Math. Soc. 125 (1995) 17051709.

[12] I. Inchan, P. Somyot, Approximating solutions for the systems accretive operator equation, computers and mathematics with Applications 53 (2007) 1317-1324.

[13] S. Ishikawa, Fixed point and iteration of a nonexpansive mappings in a Banach spaces. Proc. Amer. Math Soc. 73 (1976) 65-71.

[14] T. Kato, Nonlinear semigroups and evolution equation, J. Math. Soc. Japan 19 (1967) 502-508. 
[15] L. S. Liu, Ishikawa and Mann iterative process with errors for nonlinear strongly accretive mappings in Banach spaces, J. Math. Anal. Appl. 194 (1995) 114-125.

[16] W. R. Mann, Mean value methods in iteration, Proc. Amer. Math. Soc. 4 (1953) 506-510.

[17] R. H. Martin Jr., Differential equation on closed subsets of Banach space, Trans. Amer. Math. Soc. 179 (1973) 399-414.

[18] M. A. Noor, Three-step iterative algorithms for multivalued quasi variational inclusions, J. Math Anal. Appl. 255 (2001) 589=604.

[19] M. A. Noor, T. M. Rassias, Z. Hung, Three-step iteration for nonlinear accretive operator equations, J. Math. Anal. Appl. 274 (2002) 59-68.

[20] M.O. Osilike, Iterative solution of nonlinear equation of the $\phi$-strongly accretive type, J. Math. Anal. Appl. 200 (1996) 259-271.

[21] M. O. Osilike, Ishikawa and Mann iteration methods with errors for nonlinear equations of the accretive type, J. Math. Anal. Appl. 213 (1997) 91-105.

[22] S. Plubteing, R. Wangkeeree, Strong convergence theorems for multi-step Noor iterations with errorsin Banach spaces, J. Math. Anal. Appl. 321 (2006) 10-23.

[23] A. Ravi-P, O. Donal, S.D.R., Fixed point theory for Lipschitzian -type Mappings, Springer, (2009).

[24] K.K. Tan, H.K. Xu, Iterative solutions to nonlinear equations of strongly accretive operators in Banach spaces, J. Math. Anal. Appl. 178 (1993) 9-21.
[25] Y.Xu, Ishikawa and Mann iterative processes with errors for nonlinear strongly accretive operator euations, J. Math. Anal. Apll. 224 (1998) 91101.

[26] H. Zhous, Some convergence theorems for the Ishikawa iterative sequences of certain nonlinear operators in uniformly smooth Banach spaces, Acta Math. Sinica 40 (1997) 751-758. 